\title{
Formando historiadores na era digital: concepções e ferramentas
}

\section{Training historians in the digital age: concepts and tools}

\begin{abstract}
Alexandre Fortes*
Resumo: Este artigo aborda os desafios de renovação do processo de formação de profissionais de História num contexto global crescentemente marcado pela onipresença das tecnologias de informação em todas as dimensões da vida social. Analisamos experiências pedagógicas que temos desenvolvido recentemente, fortemente inspiradas pelas reflexões teórico-metodológicas do historiador norte-americano T. Mills Kelly. Destacamos a necessária relação entre, de um lado, uma abordagem crítica em relação ao poder das grandes corporações tecnológicas no mundo contemporâneo e, de outro, a apropriação de ferramentas computacionais que ajudem a viabilizar projetos contra-hegemônicos no campo da História.

Palavras-chave: história digital; ensino de História; humanidades digitais.
\end{abstract}

Abstract: This article addresses the challenges of renewing the professional training of historians in a global context increasingly characterized by the ubiquity of information technologies in all dimensions of social life. We analyze our recent pedagogic experiences, strongly inspired in the theoretical-methodological reflections by US historian T. Mills Kelly. We highlight the necessary relationship between, on the one side, a critical approach regarding the power of the big technological corporations in contemporary world e, on the other hand, the appropriation of computing tools that may be useful in the development of anti-hegemonic projects in the field of History.

Keywords: Digital History; Professional Training in History; Digital Humanities.

* Doutor em História pela Universidade Estadual de Campinas (Unicamp). Professor Associado do Departamento de História do Instituto Multidisciplinar da Universidade Federal Rural do Rio de Janeiro (UFRRJ). Atua nos programas de pós-graduação em História e em Humanidades Digitais da mesma instituição, ambos com apoio do PROAP-CAPES. Bolsista de Produtividade do CNPq e Cientista do Nosso Estado (FAPERJ). E-mail: fortes. ufrrj@gmail.com. ORCID: https://orcid.org/0000-0002-3728-2318. 
0 IMPACTO trazido pela aceleração das inovações e da difusão das tecnologias digitais ao longo das últimas décadas vem desafiando os educadores atuantes em todos os níveis de ensino e nas mais diversas áreas de conhecimento a repensar currículos e práticas pedagógicas.

A sociedade atual produz, difunde e processa uma enorme quantidade de informação de maneira automatizada e veloz. O aparato científico e tecnológico que sustenta esse processo, ao mesmo tempo que funciona como vetor de transformação das estruturas sociais, também fornece meios e métodos inovadores para a investigação dessas transformações em toda a sua complexidade. A constituição da comunidade interdisciplinar de práticas denominada Humanidades Digitais ${ }^{1}$ resulta das reflexões de pesquisadores de diversas áreas de conhecimento sobre as consequências da disseminação de tecnologias eletrônicas de informação sobre os processos de geração, preservação e difusão do conhecimento sobre as sociedades humanas. Reflete também o profundo impacto da chamada Era Digital sobre a atuação dos profissionais que se dedicam à análise e ao enfrentamento dos mais variados problemas sociais, um fenômeno bastante perceptível no campo da História. ${ }^{2}$ Relaciona-se, ainda, à necessidade crescente de aprofundamento da reflexão crítica sobre os potenciais, riscos e desafios gerados pela crescente penetração da tecnologia digital em todos os aspectos da vida humana.

A pandemia de covid-19, ao tornar impositiva a experiência de ensino remoto, por um lado expôs as fragilidades das instituições e dos profissionais de ensino para lidar com as novas tecnologias. De outro lado, porém, revelou uma grande capacidade para o desenvolvimento de soluções criativas que, ao menos no âmbito do ensino superior, geraram resultados expressivos após períodos de adaptação relativamente curtos. Não se trata de cair na tentação de transformar necessidade em virtude. Porém, é possível afirmar com certa segurança que, ao menos no caso das universidades públicas brasileiras, a contingência de adoção do ensino remoto emergencial obrigou a comunidade acadêmica a dar uma prioridade inédita ao debate de temas de extrema relevância para a prática educativa, tais como os desafios inerentes ao processo de aprendizagem, os potenciais e limites de diferentes metodologias de ensino e o impacto das condições socioeconômicas dos estudantes sobre seu desempenho. ${ }^{3} \mathrm{~A}$ situação de excepcionalidade trazida pela pandemia também confrontou as instituições com os problemas das desigualdades no que tange ao acesso à tecnologia digital (equipamentos, conexão, softwares, capacitação e ambientes de estudo, dentre outros).

1 AQUINO, Israel. As Digital Humanities como uma comunidade de práticas: entrevista com o professor Daniel Alves (IHC/NOVA FCSH), v. 12, n. 26, p. 22, 2020.

2 FORTES, Alexandre; ALVIM, Leandro Guimarães Marques. Evidências, códigos e classificações: o ofício do historiador e o mundo digital. Esboços: histórias em contextos globais, v. 27, n. 45, p. 207-227, 2020.

3 RONDINI, Carina Alexandra; PEDRO, Ketilin Mayra; DUARTE, Cláudia dos Santos. Pandemia de covid-19 e o ensino remoto emergencial: Mudanças na práxis docente. Interfaces Científicas - Educação, v. 10, n. 1, p. 41-57, 2020. 
A experiência de adaptação de grande parte dos componentes curriculares ao ensino remoto também vem contribuindo para uma maior sensibilização em relação à importância do desenvolvimento de estratégias institucionais que fortaleçam as infraestruturas computacionais, ampliem o leque de plataformas relevantes para as atividades de ensino pesquisa e extensão e avancem na integração de ferramentas computacionais ao processo formativo dos discentes, visando a prepará-los para a atuação profissional num contexto em que a tecnologia digital torna-se cada vez mais onipresente.

O Programa de Pós-Graduação em Humanidades Digitais do Instituto Multidisciplinar, campus de Nova Iguaçu da UFRRJ, proporciona um locus privilegiado para o desenvolvimento de projetos voltados ao enfrentamento dos desafios mencionados acima. Nascido a partir das experiências de colaboração interdisciplinar entre docentes atuantes em diversas licenciaturas e colegas da Ciência da Computação e de Sistemas de Informação, o PPGIHD tem contribuído para o fortalecimento do Centro de Documentação e Imagem (CEDIM), uma das principais estruturas institucionais de pesquisa existentes no âmbito do IM-UFRRJ.

O CEDIM integra docentes e discentes de graduação e de pós-graduação na captação, digitalização, catalogação e disponibilização de fundos documentais relevantes para a pesquisa sobre a história da Baixada Fluminense e sobre outras temáticas no campo da História Social. O centro se constitui em um espaço de apoio à pesquisa, ao ensino e à extensão para alunos, professores e comunidade acadêmica em geral, no qual ocorre a supervisão, acompanhamento e orientação de trabalhos desenvolvidos por bolsistas de iniciação científica e extensão. Desenvolve ainda atividades de difusão científica, tais como debates, seminários, lives e lançamentos de livros sobre temáticas afins. O CEDIM também gerencia uma comunidade de acervos digitais resultantes do trabalho da sua equipe no Repositório Institucional RIMA, desenvolvido com recursos de um projeto na FAPERJ entre 2014 e 2016 (http://rima.im.ufrrj.br:8080/ jspui/handle/1235813/2). Durante os primeiros meses da pandemia, a equipe do CEDIM participou de cursos visando a adquirir domínio do software livre Omeka, que passará a ser utilizado para a geração de exposições virtuais com o seu acervo e para a oferta de atividades de capacitação para discentes da UFRRJ e das redes públicas de ensino da Baixada Fluminense, possibilitando a incorporação dessa ferramenta como elemento de dinamização do ensino de História. ${ }^{4}$

É nesse contexto institucional que temos desenvolvido as recentes experiências de ensino no campo da História Digital que são analisadas neste artigo.

4 RIBEIRO, Felipe Augusto dos Santos et al. Explorando os potenciais da história digital: a experiência do Centro de Documentação e Imagem da Universidade Federal Rural do Rio de Janeiro - Campus de Nova Iguaçu. Estudos Históricos, Rio de Janeiro, v. 33, n. 69, p. 152-172, 2020. 


\section{Prelúdio: a dimensão política da história digital}

EMBORA A ÊNFASE deste trabalho recaia sobre o aprendizado do uso de alguns tipos de softwares na formação dos profissionais de História, é importante destacar que as experiências pedagógicas no campo da história digital oferecem também um espaço privilegiado para a necessária reflexão sobre questões políticas de extrema relevância no mundo atual. Os estudantes que chegam à universidade atualmente cresceram em um mundo no qual o poder da tecnologia digital alcançou profundidade e dimensões inconcebíveis há duas ou três décadas, quando boa parte dos atuais docentes do ensino superior iniciou a sua formação profissional. Em 2020, das dez empresas mais valiosas do mundo, sete poderiam ser classificadas como grandes corporações tecnológicas. ${ }^{5} \mathrm{~A}$ reflexão sobre as particularidades da atual configuração do capitalismo impõe-se como um aspecto fundamental do debate sobre o papel do historiador na sociedade, que deve orientar o processo de formação profissional no nosso ofício.

A difusão do Big Data Analytics, ou seja, da capacidade de identificar padrões ocultos a partir da análise de massas descomunais de dados geradas continuamente pela humanidade em todo o mundo a partir do momento em que a tecnologia digital foi incorporada ao cotidiano, abre grandes perspectivas para o avanço do conhecimento científico. ${ }^{6}$ Por outro lado, esse fenômeno suscita preocupações e críticas pertinentes pelos riscos trazidos à privacidade e pelos impactos nefastos gerados pelos seus usos inescrupulosos em diversas esferas, sejam elas comerciais, relacionadas à propaganda política ou mesmo ao fortalecimento da capacidade de repressão e violação dos direitos humanos por parte de órgãos estatais. ${ }^{7}$

O universo acadêmico não está imune ao poder das grandes corporações tecnológicas. Uma análise de 45 milhões de artigos indexados na Web of Science entre 1973 e 2013, período no qual os periódicos impressos foram gradualmente sendo substituídos pelos digitais, revelou uma concentração progressiva em revistas pertencentes a cinco grandes grupos, que ao final do período respondiam por $50 \%$ do total mundial de publicações. ${ }^{8}$ Esses mesmos grupos controlam crescentemente as plataformas utilizadas para análise bibliométrica do impacto da produção científica, utilizadas pelas agências de fomento na definição dos seus critérios da avaliação de produtividade dos pesquisadores e na qualidade dos programas de pós-graduação, assim como de ferramentas de gestão vendidas às instituições visando a aumentar sua competitividade. No que diz respeito especificamente à pesquisa histórica, algumas dessas corporações já identificaram o potencial representado pela oferta de acesso

5 Biggest companies in the world by market cap 2020, Statista. Disponível em: https://www.statista.com/ statistics/263264/top-companies-in-the-world-by-market-capitalization/. Acesso em: 20 abr. 2021.

6 SAGIROGLU, Seref; SINANC, Duygu. Big Data: A Review. In: SMARI, Waleed W. (org.), 2013 International Conference on Collaboration Technologies and Systems (CTS 2013): San Diego, California, USA, 20 24 May 2013; Piscataway, NJ: IEEE, 2013, p. 42-47.

7 TENE, Omer; POLONETSKY, Jules. Big data for all: Privacy and user control in the age of analytics, Northwestern Journal of Technology and Intellectual Property, v. 11, n. 5, p. 38, 2013.

8 LARIVIÈRE, Vincent; HAUSTEIN, Stefanie; MONGEON, Philippe. The oligopoly of academic publishers in the digital era. PLOS ONE, v. 10, n. 6, p. e0127502, 2015. 
pago a coleções exclusivas de fontes originais digitalizadas, acopladas a ferramentas exclusivas para a mineração de dados em fontes textuais. ${ }^{9}$

Nesse contexto de crescente influência dos oligopólios tecnológicos sobre os sistemas de regulação e difusão da produção científica, ocorrem alguns fenômenos paradoxais. Um serviço fundamental oferecido pela CAPES aos pesquisadores brasileiros, o Portal de Periódicos, custou aos cofres públicos em 2020 cerca de 480 milhões de reais, equivalendo a $21 \%$ dos gastos da mesma agência em todas as suas modalidades de bolsas de estudo. ${ }^{10} \mathrm{Em}$ função disso, já há algum tempo, vozes importantes da comunidade científica nacional questionam se parte desses recursos não deveria estar sendo direcionada a apoiar o desenvolvimento de ferramentas de acesso aberto, como portais de periódicos e repositórios institucionais. No momento em que escrevemos este artigo, por exemplo, a Hemeroteca Digital da Biblioteca Nacional, que desde a sua criação trouxe um impulso extraordinário ao avanço da pesquisa histórica no país, está fora do ar em função de um ataque hacker, provavelmente resultante de protocolos de segurança defasados e manutenção deficiente. Essa, infelizmente, é uma situação relativamente comum diante da escassez de recursos enfrentada pelas instituições de ciência, tecnologia, educação e cultura no país nos últimos anos.

Considerando essas várias dimensões da incidência dos interesses privados sobre as condições de produção e circulação do conhecimento científico, os historiadores não podem se comportar diante do mundo da tecnologia digital como meros consumidores desinformados. O engajamento crítico deve ser estimulado tanto dentro de sala de aula quanto na formulação de projetos interdisciplinares voltados ao fortalecimento das infraestruturas computacionais das instituições de ensino e pesquisa. Todos os segmentos da comunidade acadêmica devem se engajar na construção de políticas institucionais de estímulo e capacitação voltadas ao uso do software livre, ao acesso aberto e à ciência aberta. ${ }^{11}$ Não se trata aqui de defender uma atitude inflexível de banimento do uso de softwares e serviços privados, mas de compreender os custos e riscos gerados pela acomodação pessoal e coletiva diante da extraordinária concentração de poder nas mãos do Big Tech. Acima de tudo, trata-se de valorizar a capacidade singular que as instituições de ensino superior e pesquisa possuem para protagonizar um processo de apropriação ativa da vasta gama já existente de ferramentas computacionais livres, de capacitação interna e externa de usuários na sua aplicação a atividades de ensino, pesquisa e extensão, assim como de desenvolvimento de novas aplicações sem finalidade comercial.

Formar cidadã(o)s e profissionais conscientes e ativos na sua relação com um mundo dominado pela tecnologia digital implica abrir espaços para esses temas nas estruturas

9 Ver, por exemplo: https://www.cengage.com/search/showresults.do?N=197+4294891079.

10 Ver: https://www.gov.br/capes/pt-br/acesso-a-informacao/institucional/orcamento-evolucao-em-reais.

11 Para um exemplo de política de Ciência Aberta que já está tendo impacto significativo na alteração do panorama da produção científica mundial, ver as diretrizes estabelecidas pela União Europeia: https://ec.europa.eu/ info/sites/info/files/research_and_innovation/knowledge_publications_tools_and_data/documents/ec_rtd_ factsheet-open-science_2019.jpdf. 
curriculares, nos colegiados, nos ciclos de debates, nas associações científicas e em qualquer outro ambiente relevante da vida acadêmica.

\section{Repensando o ensino de História}

EM "Teaching history in the digital age", ${ }^{12}$ T. Mills Kelly chama a atenção para as profundas transformações na relação com o conhecimento histórico à medida que gerações nascidas após o advento da Web 2.0 chegam ao sistema de ensino. Não se trata apenas de jovens que crescem num contexto social permeado cada vez mais pelas tecnologias computacionais, mas também de indivíduos que, desde a mais tenra idade, criam conteúdos digitais (textos, fotos, memes, áudios, vídeos etc.) e os difundem por um leque variado de redes sociais, tendo ao alcance das mãos ferramentas cada vez mais amigáveis e poderosas de manipulação dessas diversas mídias.

Nesse contexto, acentua-se a obsolescência dos métodos tradicionais de ensino de História. Kelly destaca que pesquisas recentes demonstram que, apesar de décadas de debates sobre a necessidade de renovar o ensino de História, aulas expositivas continuam, em muitos casos, a ser praticamente o único recurso didático empregado, apesar de estar demonstrado que a assimilação das informações assim fornecidas é inferior a $20 \%$. Por outro lado, algumas metodologias de ensino que ainda são tratadas como inovações, tais como a análise de fontes históricas originais, foram propostas já no final do século XIX, mas continuam a desempenhar um papel secundário. No ensino superior, a forma mais usual de produto demandado dos estudantes para efeitos de avaliação são pequenos ensaios sobre a bibliografia utilizada em cada disciplina.

O contexto de atuação profissional dos historiadores também tem se tornado cada vez mais desafiador. Como destacam Rees e Huf, nossos alunos terão que lidar com:

o imperativo de formular novas narrativas históricas que iluminem e permitam enfrentar as crises ecológica, econômica e política correntes, enquanto encaram a crescente precariedade acadêmica e a ansiedade e depressão a ela associadas. ${ }^{13}$

Os desafios pedagógicos, na visão de Kelly, também possuem várias dimensões. O primeiro deles diz respeito a compreender o que constitui o aprendizado de História e como ele ocorre. Para o historiador norte-americano, os estudantes devem ser ensinados, em primeiro lugar, a analisar e esclarecer peças de evidência separadamente, o que envolve questionar as evidências disponíveis, buscar comparações que as iluminem e avaliar criticamente as fontes de informação. Num segundo momento, trata-se de articular em narrativas os conjuntos de evidências submetidos aos crivos mencionados acima. Por fim, é fundamental resgatar a dimensão humana do processo histórico, ou seja, a

12 KELLY, T. M. Teaching History in the Digital Age. Ann Arbor: University of Michigan Press, 2013.

13 REES, Yves; HUF, Ben. Training historians in urgent times. History Australia, p. 22, 2020. p. 272. 
experiência. A investigação de significados conflitantes atribuídos aos mesmos fenômenos e o aprendizado relativo a navegar a tensão entre familiaridade e estranhamento em relação ao passado são elementos complementares importantes a serem trabalhados visando a aguçar a capacidade de interpretação dos discentes.

O conjunto de habilidades cognitivas a serem desenvolvidas no ensino de História, na visão do autor, podem ser sintetizadas na seguinte matriz:

\section{Quadro 1: elaboração própria baseado em Kelly}

\begin{tabular}{|l|l|l|}
\hline $\begin{array}{l}\text { Diferença entre fontes } \\
\text { primárias e secundárias }\end{array}$ & $\begin{array}{l}\text { Reconhecer estranhamento } \\
\text { frente ao passado sem se } \\
\text { alhear dele }\end{array}$ & $\begin{array}{l}\text { Formular indagações: O que } \\
\text { ocorreu? Por que desta forma? }\end{array}$ \\
\hline Buscar a "fonte da fonte" & $\begin{array}{l}\text { Julgar evidências } \\
\text { comparativamente }\end{array}$ & $\begin{array}{l}\text { Reconhecer o papel da } \\
\text { causalidade }\end{array}$ \\
\hline $\begin{array}{l}\text { Buscar informação sobre } \\
\text { autoridade da fonte }\end{array}$ & $\begin{array}{l}\text { Reconhecer o que a evidência } \\
\text { mostra e o que não mostra }\end{array}$ & $\begin{array}{l}\text { Criticar evidências nos seus } \\
\text { próprios termos e em perspectiva } \\
\text { analítica }\end{array}$ \\
\hline $\begin{array}{l}\text { Ordenar fontes } \\
\text { cronologicamente }\end{array}$ & $\begin{array}{l}\text { Reconhecer que as pessoas têm } \\
\text { compreensão diferente sobre os } \\
\text { acontecimentos }\end{array}$ & $\begin{array}{l}\text { Reconhecer linhas de } \\
\text { argumentação do pensamento } \\
\text { histórico }\end{array}$ \\
\hline $\begin{array}{l}\text { Construir argumento original } \\
\text { baseado em evidências }\end{array}$ & "Triangular" entre as fontes & $\begin{array}{l}\text { Apresentar passado de forma } \\
\text { clara (escrita ou mídia) }\end{array}$ \\
\hline
\end{tabular}

Fonte: KELLY, op. cit., 2013, p. 22-23.

Ao mesmo tempo, Kelly aponta a necessidade de reflexão sobre o crescente choque cultural entre professores e alunos no que diz respeito a conceitos-chave para a disciplina histórica, tais como a originalidade das fontes. Um dos exemplos citados é o de um aluno que manifestou seu incômodo com a trilha sonora épica de um cinejornal sobre o Tribunal de Nuremberg exibido em sala de aula e, no dia seguinte, ofereceu ao professor uma versão editada do mesmo vídeo tendo ao fundo um réquiem de Mozart. A iniciativa pegou o docente desprevenido, mas sua surpresa foi maior ao constatar que a maior parte da turma não via nenhum problema na hipótese de que a fonte "original" fosse substituída pela versão editada, considerada "melhor". ${ }^{14}$

O historiador norte-americano argumenta que ao invés de censurar esse ímpeto de intervenção sobre as fontes, em que a "autenticidade" é mais valorizada do que a "originalidade", obteremos resultados mais positivos se partirmos deles para suscitar nos alunos a reflexão sobre quais os cuidados epistemológicos e metodológicos necessários para que eles possam dar origem a um processo de aprendizado que atenda aos critérios elencados no quadro acima. Afinal de contas, recorda Kelly, ao analisar e sintetizar documentos, cruzar diferentes fontes, cotejá-las com a bibliografia existente e elaborar novos trabalhos historiográficos, os

14 KELLY, op. cit., 2013, p. 1-9. 
historiadores também manipulam as evidências, embora essa manipulação seja disciplinada pelos padrões metodológicos e éticos do ofício.

O caminho proposto por Kelly para abordar simultaneamente a necessidade de atualização da metodologia de ensino de História e a canalização dos potenciais de geração de conteúdos digitais dos atuais estudantes é a incorporação de ferramentas digitais ao processo de ensino e o reconhecimento de produtos digitais (webpages, blogs, exposições virtuais, bibliotecas digitais, verbetes de Wikipedia, perfis de redes sociais, canais de vídeos no Youtube etc.) como produtos alternativos ou complementares à produção textual tradicional nos processos de avaliação de aprendizagem. As ferramentas digitais, aponta o autor, não são soluções mágicas, mas utilizá-las para ensinar os alunos a "fazer história" pode ser uma boa alternativa para conciliar o seu desejo por certezas com a devoção dos historiadores profissionais à incerteza. ${ }^{15}$

\section{Experiências preliminares}

INSPIRADO pelas reflexões apresentadas na abertura deste texto e pelas provocações e exemplos de Kelly, tenho iniciado algumas experiências de ensino de História Digital tanto no âmbito da pós-graduação quanto, mais recentemente, na graduação. A primeira delas ocorreu no segundo semestre de 2019, em uma pequena turma no mestrado de Humanidades Digitais (PPGIHD), tendo como alunos externos duas alunas do Programa de Pós-Graduação em História da UFRRJ (PPHR) e um doutorando da Universidade Federal Fluminense. Contamos também com a participação de professores visitantes para aulas específicas, como Ricardo Pimenta e Josir Gomes (ambos vinculados ao Instituto Brasileiro de Informação em Ciência e Tecnologia - IBICT), que compartilharam com a turma a experiência do Laboratório em Rede de Humanidades Digitais (LARHUD). Numa segunda participação especial, o professor Leandro Alvim, do curso de Ciência da Computação do IM-UFRRJ, apresentou um panorama das metodologias de mineração de dados aplicadas à análise histórica, iniciando um diálogo que deu origem a um artigo em coautoria que publicamos no ano seguinte. ${ }^{16}$ Embora os alunos daquela turma tenham sido já estimulados à elaboração de projetos construídos com ferramentas digitais, a orientação metodológica necessária para viabilizar essa intenção não estava plenamente amadurecida e os trabalhos finais se dividiram entre revisões da bibliografia trabalhada e propostas preliminares, exemplificando pontualmente a utilização de algumas ferramentas computacionais auxiliares à pesquisa histórica.

A segunda turma de História Digital do PPGIHD formou-se no segundo semestre de 2020, já sob pleno impacto da pandemia de covid-19. O ensino remoto já se impunha como uma necessidade, e tratamos de pensar em como extrair o máximo dos potenciais

15 Ibidem, p. 24

16 FORTES; ALVIM, Evidências, códigos e classificações. 
que essa nova situação abria, assim como de minimizar os prejuízos que ela poderia trazer ao aprendizado. Foi criada uma turma no Google Sala de Aula, divulgada via Facebook, na qual um volume considerável de bibliografia, links para websites e vídeos relevantes para a temática da disciplina foram disponibilizados. Diversos professores e estudantes solicitaram autorização para participar desse ambiente de aprendizado virtual apenas para ter acesso ao material. A turma que cursou efetivamente a disciplina também possuía grande diversidade, sendo integrada por treze discentes de três programas de pós-graduação diferentes da UFRRJ (Educação, História e Humanidades Digitais), além de seis alunos externos de instituições de outros estados (Rio Grande do Sul, São Paulo, Minas Gerais e Piauí) e de uma ouvinte vinculada ao CONICET (Argentina).

As sessões síncronas foram realizadas semanalmente por meio do sistema de videoconferência da Rede Nacional de Pesquisa (RNP), intercalando aulas teóricas com "oficinas de ferramentas" de três tipos:

1. Gerenciador de referências bibliográficas (Zotero);

2. Plataformas para criação de exposições virtuais (Omeka e StoryMap);

3. Software de análise de dados qualitativos (MaxQDA).

Essas ferramentas, de utilização relativamente simples, oferecem funcionalidades complementares de alta relevância para a formação e a prática profissional no campo da História.

O Zotero, assim como outros softwares similares, possibilita a organização dos metadados de referências bibliográficas (autoria, data, título, páginas, editora etc.), seja a partir do preenchimento manual ou da importação automatizada de itens (livros, capítulos, artigos, notícias, sites etc.) individuais ou de conjuntos localizados a partir de buscas nos catálogos eletrônicos de bibliotecas e portais de periódicos. A inserção de referências bibliográficas e a geração da bibliografia de cada trabalho escrito pelo usuário são automatizadas a partir da conexão do software com o editor de texto. É possível instalar um plug-in no navegador utilizado para acesso à internet, facilitando a importação dos itens. Os arquivos correspondentes a cada referência podem ser anexados à ficha de metadados correspondente, a fim de facilitar a gestão dos grandes volumes de arquivos digitais acumulados pelos pesquisadores. Ao cadastrar uma conta no servidor do Zotero, o usuário gera um backup em nuvem das suas referências e passa a ter a oportunidade de construir bibliografias compartilhadas com outros usuários interessados nos mesmos temas ou autores.

Para além dos aspectos práticos mencionados acima, a utilização de um programa dessa natureza contribui para uma melhor estruturação do processo de construção textual, assim como para organizar o diálogo entre as questões orientadoras dos projetos de pesquisa, as evidências selecionadas nas fontes e a bibliografia relevante. É importante observar que esses processos se complexificam à medida que o acesso à informação se expande e se acelera, o que vai tornando cada vez mais difícil operá-los com recursos tradicionais 
(anotações manuais ou em editores de texto, por exemplo) sem que haja expressiva perda de tempo ou subutilização dos resultados da pesquisa realizada. Ou seja, muitas vezes informações e referências importantes com as quais o pesquisador já teve contato em algum momento são "perdidas" nos seus suportes físicos (cadernos, fichas, pastas etc.) ou mesmo dentro dos computadores. Por outro lado, o uso de um instrumento como o Zotero também permite aguçar a consciência dos estudantes sobre a distinção entre as diversas "camadas textuais" (conteúdo dos textos, metadados, resumos, identificação de informações relevantes, anotações relacionando o item em análise com outros etc.) que se constituem em matéria-prima do processo que, inspirado por Marc Bloch, denominei de "classificação racional das informações em busca de uma progressiva inteligibilidade do processo histórico". ${ }^{17}$

O segundo tipo de ferramenta trabalhado na disciplina são plataformas destinadas à criação de exposições virtuais: StoryMap e Omeka (esta última, assim como o Zotero, desenvolvida pelo Roy Rosenzweig Center for History and New Media da George Mason University). A exposição virtual é instrumento de grande potencial para o desenvolvimento da "história pública digital". ${ }^{18}$ A elaboração desse tipo de projeto, assim como ocorre com os gerenciadores de referências bibliográficas, realça a importância dos metadados, nesse caso referentes às fontes primárias, não à bibliografia. Mas eles acrescentam outra dimensão relevante no processo de formação profissional do historiador, que é o da curadoria, envolvendo atividades como a organização de coleções documentais, a seleção e ordenamento de itens a serem apresentados ao público e a elaboração de textos informativos objetivos e didáticos. Assim como o uso de uma ferramenta como o Zotero demanda o diálogo interdisciplinar com a biblioteconomia e a arquivística (de forma mais ampla, a ciência da informação), plataformas como Omeka e o StoryMaps remetem à intersecção entre história e museografia.

A Baixada Fluminense, onde se situam os dois maiores câmpus, da UFRRJ (Seropédica e Nova Iguaçu), constitui-se em uma região extremamente carente de instituições dedicadas à histórica e fortemente estigmatizada pela associação à pobreza e à violência, assim como ocorre com outras regiões beneficiadas pela expansão da rede federal de ensino superior na década de 2000. É possível afirmar, também, que a proximidade e contraste em relação ao Rio de Janeiro, ex-capital do país, referência fundamental da cultura nacional brasileira e grande polo turístico, alimenta o descaso em relação à pesquisa e ensino da história da Baixada Fluminense, perpetuando obstáculos à formação de uma identidade coletiva positiva entre os seus habitantes.

A presença da universidade pública em locais com essas características tem contribuído para fomentar a geração de conhecimento sobre a história regional e sobre as manifestações locais de temas relevantes para o debate historiográfico nacional e internacional. $\mathrm{O}$ trabalho

17 FORTES; ALVIM, Evidências, códigos e classificações. p. 210.

18 NOIRET, Serge. História Pública Digital | Digital Public History. Liinc em Revista, v. 11, n. 1, 2015; MATEUS, João Mascarenhas; VEIGA, Ivo. Portugal builds: uma plataforma digital para a história da construção em Portugal nos séculos XIX e XX. Estudos Históricos, Rio de Janeiro, v. 33, n. 69, p. 88-110, 2020. 
do Centro de Documentação e Imagem do IM-UFRRJ trouxe uma contribuição significativa nesse sentido, ao digitalizar e disponibilizar conjuntos fundamentais de documentos históricos com ênfase no contexto regional. A capacitação de estudantes e profissionais de história para a construção de exposições virtuais pode potencializar esse processo e estreitar as relações entre pesquisa, sala de aula e público em geral, como pode ser exemplificado pela exposição virtual Locais de Memória - Dom Adriano Hypólito, criada pelo professor Samuel Henriques como parte da elaboração da sua dissertação defendida no mestrado profissional em ensino de História (ProfHistória) da UERJ-São Gonçalo. ${ }^{19}$ Henriques utilizou as fontes digitalizadas do arquivo da Cúria Diocesana de Nova Iguaçu, disponibilizadas pelo CEDIM e o StoryMap, para apresentar de forma didática e georreferenciada alguns locais onde ocorreram fatos e processos marcantes na trajetória do bispo católico que alcançou projeção internacional por seu papel na resistência à ditadura militar, na defesa dos direitos humanos e no apoio a movimentos sociais na região.

O terceiro tipo de ferramenta apresentada aos alunos nas nossas aulas de História Digital são os softwares de apoio à análise de dados qualitativos. A característica comum a esse tipo de programa é a possibilidade de identificar trechos ou partes das fontes analisadas (texto, imagem, áudio, vídeo etc.) com etiquetas descritivas criadas pelo próprio pesquisador, que podem ser organizadas e reorganizadas em conjuntos de vários níveis hierárquicos. Esse processo de "codificação" baseia-se na abordagem da grounded theory, ${ }^{20}$ que enfatiza o papel da classificação e ordenamento das evidências empíricas no desenvolvimento de generalizações com embasamento consistente, a partir das quais análises e sínteses originais podem ser elaboradas.

Uma limitação ainda presente no nosso trabalho docente com este tipo de ferramenta é que, embora existam diversos softwares livres voltado à Qualitative Data Analysis, ${ }^{21}$ ainda não possuímos experiência na sua utilização. Desse modo, ao contrário dos casos anteriores, ainda não temos condições de passar aos estudantes orientações específicas para uma rápida capacitação ao uso de funções básicas. Ainda assim, a apresentação dos projetos que temos desenvolvido com o MaxQDA, assim como as leituras sobre o trabalho de outros colegas com o similar Atlas TI, ${ }^{22}$ ambos softwares proprietários, proporcionam uma visão panorâmica sobre o potencial do suporte computacional à análise qualitativa na produção de conhecimento histórico original. Dessa forma, pode-se alcançar avanços significativos no cruzamento da

19 HENRIQUES, Samuel de Almeida. Dom Adriano e ensino de história para os direitos humanos: um mapa digital sobre locais de memória e resistência à Ditadura em Nova Iguaçu. Dissertação (Mestrado) - Programa de Pós-Graduação em Ensino de História, Curso de Mestrado Profissional em Rede Nacional ProfHistória, Universidade do Estado do Rio de Janeiro, São Gonçalo, 2020.

20 GLASER, Barney G.; STRAUSS, Anselm L. The discovery of grounded theory: strategies for qualitative research. Chicago: Aldine Pub. Co, 1967; GLASER, Barney G. More grounded theory methodology: a reader. Mill Valley: Sociology Press, 1994.

21 SCHOLARLY COMMONS. LibGuides: Qualitative Data Analysis Software: Free Software. Disponível em: <https://guides.library.illinois.edu/c.php?g=348074\&p=2346107>. Acesso em: 20 abr. 2021.

22 BRASIL, Eric; NASCIMENTO, Leonardo Fernandes. História digital: reflexões a partir da hemeroteca digital brasileira e do uso de CAQDAS na reelaboração da pesquisa histórica. Estudos Históricos, Rio de Janeiro, v. 33, n. 69 , p. $196-219,2020$. 
maior diversidade possível de fontes e no cotejamento do resultado da análise das evidências empíricas com as interpretações propostas para fenômenos similares ou conexos em diversos campos de produção historiográfica. Da mesma forma, assim como comentamos em relação aos gerenciadores de referências bibliográficas, os programas de QDA também contribuem para aguçar a percepção em relação à navegação de "múltiplos níveis de textualidade" e ao processo de "classificação racional de informações" como aspectos inerentes ao ofício do historiador.

Como diretrizes gerais para o avanço dessa incorporação de ferramentas computacionais ao processo de formação de novos historiadores, podemos mencionar: a) explorar as opções de software livre existentes para cada dimensão da atividade acadêmica; b) produzir material adequado para que os estudantes venham a deles se apropriar de forma mais rápida e efetiva; c) dialogar com os departamentos de computação das universidades a fim avaliar a possibilidade de desenvolvimento de ferramentas adequadas às demandas específicas da pesquisa histórica e de ambientes virtuais nos quais os diferentes tipos de ferramentas aqui mencionados possam ser acessados e utilizados de forma livre e integrada.

Na experiência realizada na pós-graduação em 2020 que mencionamos acima, em que o caráter prático da proposta foi mais maduro, os produtos finais elaborados pelos discentes incluíram:

1. Um canal de Youtube destinado ao compartilhamento de experiências dos discentes e egressos do mestrado profissional em ensino de História (ProfHistória);

2. Três bibliografias on-line geradas com o Zotero com os seguintes focos:

a. "História do Trabalho em Volta Redonda";

b. "Polarização Ideológica e Tecnologia no Contexto Atual";

c. Obras de interesse comum de três pós-graduandos realizando pesquisas no campo da história social.

3. Um estudo da possibilidade técnica de integração da ferramenta StArt com o Zotero na realização de levantamentos bibliográficos;

4. Uma exposição virtual gerada utilizando o Omeka, dedicada a "Red Culturas y Lenguas Indígenas";

5. Dois projetos combinando exposição virtuais no Omeka e bibliotecas digitais no Zotero sobre os temas:

a. "História do Município de Queimados";

b. "Ensino de História".

6. Um projeto de Georreferenciamento de experiências históricas de financiamento habitacional na Europa com o Google Maps;

7. Um Mapa mental de ferramentas digitais relevantes para o ensino e pesquisa de história disponibilizado no repositório aberto Zenodo.

Atualmente estamos adaptando essa proposta de ensino ao ambiente da graduação por meio de uma disciplina optativa do curso de Licenciatura em História do IM-UFRRJ. Uma novidade nessa terceira experiência foi a gravação de três tutoriais em vídeo sobre o uso do Zotero 
(Introdução, Pesquisa bibliográfica e Bibliotecas compartilhadas online), ${ }^{23}$ visando a facilitar o aprendizado dessa ferramenta pelos estudantes e a elaboração dos trabalhos finais. Ainda é cedo para avaliar os resultados nesse caso. Merecem registro, contudo, os comentários dos estudantes de que disciplinas com este enfoque deveriam constituir componentes curriculares obrigatórios oferecidos nos primeiros semestres dos cursos, pois contribuiriam para organizar o seu processo de estudo, para o desenvolvimento de projetos de pesquisa e para a elaboração dos trabalhos de conclusão de curso.

\section{Conclusão}

ESTE ARTIGO foi escrito com a intenção de compartilhar reflexões que perpassam experiências embrionárias de ensino com foco na História Digital.

Partimos de um alerta sobre a necessidade de fomentar o debate crítico em relação ao poder das grandes corporações tecnológicas no mundo atual, seu impacto sobre a vida acadêmica e sobre a importância do engajamento pessoal e institucional nos movimentos em defesa do software livre, do acesso aberto e da ciência aberta.

Num segundo momento, sintetizamos as reflexões de Kelly sobre a necessidade de repensar o ensino de História num mundo habitado por "criadores compulsivos de conteúdo digital". Conforme apontamos, o historiador norte-americano associa o aprendizado da História ao desenvolvimento de habilidades cognitivas que permitam a navegação criteriosa das massas crescentes de informação às quais os indivíduos estão atualmente expostos. Dito de outra forma, o ensino de História só responderá às demandas da sociedade atual se se renovar, visando a contribuir para a manutenção das condições de exercício da cidadania crítica e ativa num mundo de Big Data, Fake News e negacionismo.

Por fim, apresentamos a trajetória e alguns resultados preliminares da nossa prática docente recente, com ênfase na relação entre, de um lado, questões teóricas e metodológicas inerentes à História Digital e, de outro, o papel da capacitação no uso de ferramentas computacionais que oferecem recursos relevantes a diferentes âmbitos da prática profissional do historiador.

Esperamos que este trabalho contribua para estimular novas experiências e debates nesse campo emergente, e que o seu crescimento crie as condições para transformações mais ousadas e profundas nos percursos formativos oferecidos aos jovens historiadores pelas universidades brasileiras.

Recebido em 23/04/2021

Aprovado em 05/08/2021

23 Disponíveis em: https://www.youtube.com/playlist?list=PL4Ed_o0kkNNkCfyO9ulSshErhWvINBPmH. 